\title{
QUEEN'S
UNIVERSITY
BELFAST
}

\section{Association of empiric antibiotic regimen discordance with 30-day mortality in neonatal and paediatric bloodstream infection - a global retrospective cohort study}

Hsia, Y. (2021). Association of empiric antibiotic regimen discordance with 30-day mortality in neonatal and paediatric bloodstream infection - a global retrospective cohort study. The Pediatric Infectious Disease Journal. https://doi.org/10.1097/INF.0000000000002910

\section{Published in:}

The Pediatric Infectious Disease Journal

\section{Document Version:}

Peer reviewed version

Queen's University Belfast - Research Portal:

Link to publication record in Queen's University Belfast Research Portal

\section{Publisher rights}

Copyright 2020 Lippincott, Williams \& Wilkins. This is an open access Creative Commons Attribution-NonCommercial License (https://creativecommons.org/licenses/by-nc/4.0/), which permits use, distribution and reproduction for non-commercial purposes, provided the author and source are cited.

\section{General rights}

Copyright for the publications made accessible via the Queen's University Belfast Research Portal is retained by the author(s) and / or other copyright owners and it is a condition of accessing these publications that users recognise and abide by the legal requirements associated with these rights.

Take down policy

The Research Portal is Queen's institutional repository that provides access to Queen's research output. Every effort has been made to ensure that content in the Research Portal does not infringe any person's rights, or applicable UK laws. If you discover content in the Research Portal that you believe breaches copyright or violates any law, please contact openaccess@qub.ac.uk. 


\section{Association of empiric antibiotic regimen discordance with 30-day mortality in neonatal and paediatric bloodstream infection - a global retrospective cohort study.}

Authors: Aislinn Cook MSc ${ }^{1}$, Yingfen Hsia PhD ${ }^{1}$, Neal Russell MD ${ }^{1}$, Mike Sharland MD PhD' ${ }^{1}$, Kaman Cheung ${ }^{2}$, Keith Grimwood MD',4, Jack Cross ${ }^{3}$, Denise Cotrim da Cunha MD ${ }^{5}$, Gloria Regina Magalhães RN ${ }^{5}$, Hanna Renk MD ${ }^{6}$, Avni Hindocha MD7, Paddy McMaster MD7, Uduak Okomo MD PhD ${ }^{8}$, Saffiatou Darboe MSc ${ }^{8}$, Gerardo Alvarez-Uria MD $\mathrm{PhD}^{9}$, Dasaratha R Jinka MD ${ }^{9}$, Srinivas Murki DM MD ${ }^{10}$, Hemasree Kandraju DNB MD ${ }^{10}$, Dhanya Dharmapalan MD ${ }^{11}$, Susanna Esposito MD ${ }^{12}$, Sonia Bianchini MD PhD ${ }^{12}$, Kahoru Fukuoka MD ${ }^{13}$, Yuta Aizawa MD PhD ${ }^{13}$, Rodolfo Norberto Jimenez-Juarez MD ${ }^{14}$, ${ }^{15}$, Karla Ojeda-Diezbarroso MD ${ }^{14}$, Mateja Pirš PhD ${ }^{16}$, Mojca Rožič MD ${ }^{17}$, ${ }^{18}$, Suvaporn Anugulruengkitt MD PhD ${ }^{19}$, 20, Watsamon Jantarabenjakul MD PhD 19, 20, 21, Ching-Lan Cheng PhD ${ }^{22,}$ 23, Bai-Xiu Jian MSc $^{22}$, Evangelos Spyridakis MD²4, 25, Theoklis Zaoutis MD MSCE ${ }^{26,27}$, Julia Bielicki MD, PhD'

${ }^{1}$ Paediatric Infectious Diseases Research Group, St. George's University of London, London, United Kingdom ${ }^{2}$ Monash Health, Australia

${ }^{3}$ Gold Coast Health, Gold Coast, Queensland, Australia

${ }^{4}$ Griffith University, Queensland, Australia

${ }^{5}$ Hospital Infection Control Service of Hospital Federal dos Servidores do Estado, Rio de Janeiro, Brazil

6University Children's Hospital Tübingen, Department of Paediatric Cardiology, Pulmonology and Intensive Care Medicine, Tübingen, Germany

${ }^{7}$ North Manchester General Hospital, Manchester, United Kingdom

${ }^{8}$ London School of Hygiene and Tropical Medicine

${ }^{9}$ Department of Infectious Diseases, RDT Hospital, Andhra Pradesh, India

${ }^{10}$ Department of Neonatology, Fernandez Hospital, Hyderabad, India

${ }^{11}$ Dr. Yewale's Multispecialty Hospital for Children, Vashi, Navi Mumbai, India

${ }^{12}$ Pediatric Clinic, Pietro Barilla Children's Hospital, University of Parma, Parma, Italy

${ }^{13}$ Division of Infectious Diseases, Department of Paediatrics, Tokyo Metropolitan Children's Medical Center, Tokyo, Japan

${ }^{14}$ Infectious Diseases Department, Federico Gómez Children's Hospital of Mexico, Mexico City, Mexico

${ }^{15}$ Department of Pediatrics, Infectious Diseases Hospital, national Medical Center "La Raza", Mexican Institute of

Social Security, Mexico City, Mexico

${ }^{16}$ Institute of Microbiology and Immunology, Faculty of Medicine, University of Ljubljana, Ljubljana, Slovenia

${ }^{17}$ Department of Infectious Diseases and Epidemiology, Faculty of Medicine, University of Ljubljana, Ljubljana,

Slovenia

${ }^{18}$ Department of Infectious Diseases, University Medical Centre Ljubljana, Ljubljana, Slovenia

${ }^{19}$ Division of Infectious Diseases, Department of Pediatrics, Faculty of Medicine, Chulalongkorn University, Bangkok, Thailand

${ }^{20}$ Center of Excellence in Pediatric Infectious Diseases and Vaccines, Chulalongkorn University, Bangkok, Thailand

${ }^{21}$ Thai Red Cross Emerging Infectious Diseases Clinical Center, King Chulalongkorn Memorial Hospital, Bangkok

Thailand

${ }^{22}$ Institute of Clinical Pharmacy and Pharmaceutical Sciences, College of Medicine, National Cheng Kung University, Tainan City, Taiwan

${ }^{23}$ Department of Pharmacy, National Cheng Kung University Hospital, Tainan City, Taiwan

${ }^{24}$ University of Florida College of Medicine, Gainesville, FL, USA

${ }^{25}$ The Studer Family Children's Hospital at Ascension Sacred Heart, Pensacola, FL, USA

${ }^{26}$ Perelman School of Medicine at the University of Pennsylvania, Philadelphia, PA, USA

${ }^{27}$ Division of Infectious Diseases, Children's Hospital of Philadelphia, Philadelphia, PA, USA

\section{Corresponding author: Aislinn Cook}

Paediatric Infectious Diseases Research Group

St George's University of London

Cranmer Terrace

London | United Kingdom | SW17 ORE

Tel: +44 (0)2087252780

email: aicook@sgul.ac.uk

Conflicts of Interest and Source of Funding: The authors have no conflicts of interest to declare. GARPEC was funded by the Penta Foundation, Padua, Italy. The funder had no role in study design, conduct or write up.

Keywords: Bloodstream infections, empiric antibiotic therapy, antimicrobial resistance, paediatrics

Abbreviated title: Paediatric BSI empiric antibiotics and mortality: global study

Running head title: Empiric antibiotics in paediatric BSI and mortality 


\section{Abstract:}

Background: While there have been studies in adults reporting discordant empiric antibiotic treatment associated with poor outcomes, this area is relatively unexplored in children and neonates despite evidence of increasing resistance to recommended first-line treatment regimens.

Methods: Patient characteristics, antibiotic treatment, microbiology and 30-day all-cause outcome from children $<18$ years with blood-culture-confirmed bacterial BSI were collected anonymously using REDCap ${ }^{\mathrm{TM}}$ through the Global Antibiotic Prescribing and Resistance in Neonates and Children (GARPEC) network from February 2016February 2017. Concordance of early empiric antibiotic treatment was determined using EUCAST interpretive guidelines. The relationship between concordance of empiric regimen and 30-day mortality was investigated using multivariable regression.

Results: 452 children with blood-culture-positive BSI receiving early empiric antibiotics were reported by 25 hospitals in 19 countries. 60\% (273/452) were under the age of 2 years. S. aureus, E. coli and Klebsiella spp. were the most common isolates and there were 158 unique empiric regimens prescribed. 15.3\% (69/452) of patients received a discordant regimen and 7.7\% (35/452) died. 6\% (23/383) of patients with concordant regimen died compared to $17.4 \%(12 / 69)$ of patients with discordant regimen. Adjusting for age, sex, presence of comorbidity, unit type, HAI and Gram stain, the odds of 30-day mortality were $2.9(95 \% \mathrm{Cl}: 1.2-7.0, \mathrm{p}=0.015)$ for patients receiving discordant early empiric antibiotics.

Conclusions: Odds of mortality in confirmed paediatric BSI are nearly 3-fold higher for patients receiving a discordant early empiric antibiotic regimen. The impact of improved concordance of early empiric treatment on mortality, particularly in critically ill patients, needs further evaluation.

\section{Background}

There is a common understanding that rapidly treating bloodstream infections with appropriate antibiotic therapy can reduce morbidity and mortality.(1-4) Generally, inappropriate treatment in this context is defined as the cultured bacterial isolate being resistant to the empirically administered antibiotic or antibiotic combination. Early empiric treatment tends to be based on clinical presentation until microbiology results are known which can take several days.(5) Most studies that have found an association between discordant empiric antibiotic therapy and mortality have been conducted in sepsis or bloodstream infection in adults. $(1,4)$ In contrast, there are limited data in neonates and children.

Currently, the World Health Organisation (WHO) universally recommends empiric first line therapy of ampicillin and gentamicin for suspected sepsis in neonates and children which does not account for the wide variation in resistance patterns seen globally. $(6,7)$ With the rise of antimicrobial resistance, there is concern that clinicians will empirically prescribe combinations of broader-spectrum antibiotics aiming to reduce poor outcomes, in turn, increasing patient and unit level exposure.(8)

To determine the importance of concordance of empiric regimens for children, a clearer understanding of the relationship between discordant empiric regimens and adverse clinical outcomes is required. This study aims to 
explore the association between discordant empiric antibiotic therapy and 30-day all-cause mortality in children and neonates globally.

\section{Materials and Methods}

\section{Study design and study population}

A retrospective observational cohort study analysing data collected via the Global Antibiotic Resistance, Prescribing and Efficacy in Neonates and Children (GARPEC) network was performed to address the study objectives. The GARPEC network aimed to provide tools for surveillance of antibiotic prescribing and resistance data in hospitalised neonates and children.(9) Data on neonates and children with confirmed bloodstream infections (BSI) occurring between February 2016 and February 2017 were collected. Patients $<18$ years of age with a positive blood culture with a pathogen from a predefined list were included. Positive cultures of the same organism grown within 4 weeks of the initial enrolment culture were considered part of the same episode and were not recorded.

\section{Data collection}

Demographics, comorbidities, antibiotic treatment (dose, route of administration, treatment duration), routine antimicrobial susceptibility testing results, and 30-day all-cause outcome data were anonymously collected by participating centres using REDCap ${ }^{\mathrm{TM}}$ electronic data capture tools hosted at St. George's University of London. REDCap $^{\mathrm{TM}}$ (Research Electronic Data Capture) is a secure web-based application for online data entry. $(10,11)$ Data were collected voluntarily and sites received no financial incentive. All sites requiring local ethics approval received it prior to the start of data collection.

\section{Data Management}

Only patients with a monomicrobial bacterial infection were included in the final analyses.

In GARPEC, the starting and stopping of antibiotics for neonates and children contributing to the bloodstream infection dataset were recorded by calendar dates only rather than by exact date and time, and date that speciation/susceptibility of the organism was known was not recorded. Empiric antibiotic treatment was therefore classified using antibiotic start and end calendar dates and date blood culture was taken. Conservatively, we assumed a two-day window after blood culture for empiric therapy during which any antibiotic treatment given would be highly unlikely to be guided by full microbiology results.(5) Any antibiotics received during this window were considered as empiric therapy, even if they were initiated during the second day after blood culture. In addition, we considered the first regimen to be antibiotics started at the time of blood culture or up to 1 day after blood culture. 
European Committee on Antimicrobial Susceptibility Testing (EUCAST) expert rules and interpretive algorithms

$(12,13)$ were used as follows to interpret reported antibiotic susceptibility testing data:

- If the bacterial species is considered intrinsically resistant to a prescribed antibiotic according to EUCAST, susceptibility was coded as resistant regardless of reported testing results.

- Primarily, if data were available for the specific antibiotic in the prescribed treatment regimen, this was used to determine susceptibility.

- If a prescribed antibiotic was not tested, susceptibility results of antibiotics from the same class were used, for example susceptibility of an isolate to other aminoglycosides used to determine gentamicin susceptibility if gentamicin was not tested directly.

- Susceptibility to third-generation cephalosporins was based on cefotaxime or ceftriaxone, where available. If cefotaxime and ceftriaxone were not tested, susceptibility data from other third-generation cephalosporins was used.

- Susceptibility of S. aureus to broader-spectrum beta-lactams - cephalosporins and carbapenems - was derived from cefoxitin or oxacillin resistance, where available.

- Susceptibility reported as intermediate was considered resistant.

Empiric antibiotic regimen concordance was based on in vitro susceptibility findings. An antibiotic regimen was defined as concordant if the pathogen was susceptible to at least one antimicrobial in the empiric regimen. An antibiotic regimen was defined as discordant if the pathogen was not susceptible to any antibiotic in the empiric regimen. Patients with unclassifiable regimens, defined as unknown susceptibility of the pathogen to all empiric antibiotics or resistance of the pathogen to one antibiotic and unknown susceptibility for the other antibiotic(s) were excluded from analyses.

For the first empiric regimen, patients receiving no antibiotics up to 1 day after blood culture were considered part of the discordant group. We also examined these patients as a separate group.

The primary exposure of interest was concordance of the empiric antimicrobial regimen. The primary outcome was 30-day all-cause mortality. Age was grouped using International Conference on Harmonisation (ICH) classification.(14) Babies $<28$ days postnatal age at enrolment who were born at $<37$ weeks gestation were defined as preterm neonates. Babies $<28$ days postnatal age at enrolment who were born at $\geq 37$ weeks gestation were defined as term neonates. Due to a lack of sub-categories for perinatal comorbidities, it was assumed comorbidities 
classified as "perinatal" included prematurity; thus to prevent prematurity being controlled for twice for pre-term neonates, those with only one comorbidity classified as "perinatal" were not considered as having a comorbidity since their age group already accounted for their prematurity. Patients in all other age groups with a comorbidity classified as "perinatal" were considered to have at least one comorbidity (e.g. infants outside of the neonatal period at enrolment who had been born prematurely). Presence of any other comorbidity category was counted as presence of a comorbidity for all age groups. Hospital-acquired infections (HAI) were considered those with positive blood culture taken two or more days after date of admission as exact admission and antibiotic start times were unavailable. Given small sample size, we did not adjust for hospital or pathogen. Patients with incomplete data for concordance, primary outcome and relevant covariates were excluded from final analyses.

\section{Statistical Analyses}

Descriptive results were examined as relative frequency, and characteristics of survivors and non-survivors were compared using $\chi^{2}$ tests. Univariate Cochran-Mantel-Haenszel odds ratios for 30-day all-cause mortality were calculated for discordance and potential confounders.

Multivariable logistic regression was used to investigate the relationship between the concordance of the empiric antibiotic regimen and 30-day all-cause mortality. Potential confounders were selected for inclusion in the logistic regression a priori and based on results of univariate analyses. After running the a priori multivariable model, any variables not statistically significantly associated with mortality were removed for our final model. Both a priori and final models are presented. A p-value $<0.05$ was considered as statistically significant. All analyses were done in Stata (v14.2, StataCorps, USA)

\section{Results}

\section{Baseline characteristics}

The final sample size was 452 patients receiving empiric antibiotics in the first two days post-blood culture. When considering empiric regimens on the first day post blood culture only, there were 451 patients (Figure, Supplemental Digital Content 1), of which 34 did not receive any antibiotics on the first day.

Overall, $60 \%$ of patients (273/452) were under the age of two years, of which half $(141 / 273)$ were infants and children between 30 days and 2 years (overall: 141/452, 31.2\%) and a quarter (70/273) were preterm neonates (overall 70/452, 15.5\%). Patients came from 25 hospitals in 19 countries (Supplemental Digital Content 2, table). Healthcare-associated infections accounted for $47.6 \%$ (215/452) of infections. Baseline characteristics of survivors and non-survivors are summarised in Table 1. Overall, $62.2 \%$ (281/452) patients had at least one comorbidity of 
which the most common were perinatal and malignancy and most common amongst non-survivors was a perinatal condition (Tables, Supplemental Digital Content 3 and 4). Gram-negative pathogens were isolated in 261/452 (57.7\%) of infections. The three most common isolates overall were S. aureus (19.3\%), E. coli (17.9\%) and Klebsiella spp. (12.2\%). In total, 158 unique empiric antibiotic regimens were prescribed to patients (Table, Supplemental Digital Content 5). 25.1\% (113/451) of patients had a discordant first empiric regimen (given within one day after blood culture). Expectedly this was slightly lower when a longer time frame of two days post-blood culture was considered (15.3\%; 69/452).

Discordant empiric antimicrobial therapy occurred in approximately equal proportions in Gram-positive (15.7\%, 30/191) and Gram-negative infections (14.9\%, 39/261); however, a higher proportion of the deaths occurred in patients with Gram-negative pathogens of which Acinetobacter spp. and Serratia spp. had the highest mortality rates overall $(4 / 14,29 \%$ and 3/14, 23\% respectively) (Table 2). Discordant regimens by pathogen and concordance of pathogens without fatalities are in Supplemental Digital Content 6 (table) and Supplemental Digital Content 7 (table) respectively.

Due to a possible clinical reason for the subset of patients $(n=34)$ not being started on any antibiotics until more than one day post blood culture, their characteristics were also considered separately (Table 3). These 34 patients started antibiotics within the first two days after blood culture and are included in the overall cohort $(n=452)$.

Overall, 35 children died (7.7\%). Considering mortality by concordance, overall $23 / 383(6.0 \%)$ of children died in the concordant group and 12/69 (17.4\%) of children died in the discordant group ( $p=0.001)$. When considering only the first empiric regimen, $20 / 338$ (5.9\%) of children died in the concordant group and 15/113 (13.3\%) of children died in the discordant group $(p=0.011)$.

\section{Univariable Analysis}

In the unadjusted analysis, discordant empiric therapy in the first two days post blood culture was associated with a 3.3 increase in odds of 30-day mortality (95\% Cl:1.5-7.1, p=0.0011). Discordance in the first antibiotic regimen administered was associated with a 2.4 increase in odds of 30-day mortality (unadjusted, 95\%Cl:1.2-5.0, p= 0.0115). When excluding patients who did not receive antibiotics in the first day after blood culture ( $n=417)$, discordance of first antibiotic regimen was associated with 3.1 increase in odds of 30-day mortality (unadjusted, 95\%Cl:1.5-6.7, $\mathrm{p}=0.0018)$. Comorbidity, unit type, ventilation, infection type and pathogen type were also individually significantly associated with 30-day mortality (Table 4).

\section{Multivariable Analysis}


Variables associated with mortality in univariate analyses and those selected a priori (age and sex) were included in the logistic regression models. Ventilation status was not used due to strong association with unit type $(P<0.001)$. Both a priori and final models are presented (Table 5). All adjusted models had a similar magnitude of association: the highest association between discordance and death occurred in the overall cohort ( $O R=3.1, p=0.010)$ and lowest occurring in the first empiric group $(O R=2.5, p=0.023)$ when including patients not receiving any antibiotics in the first day after blood culture (Table 5).

\section{Discussion}

We found a three-fold increase in the odds of 30-day all-cause mortality associated with discordant empiric antibiotic therapy even after adjusting for other mortality risk factors, suggesting that early receipt of concordant empiric antibiotics may contribute to improving clinical outcomes. When considering just empiric antibiotics in the first day after blood culture the association persisted and was stronger when excluding patients who did not start treatment until the second day post blood culture. This stronger association suggests that there may have been a clinical reason these patients were not started on treatment (e.g. delayed until further deterioration or further results were received). These patients were predominantly children without comorbidities being treated for CAI in a non-ICU setting and only accounted for $2 / 35$ deaths. While our study did not include data on severity of illness this difference in association in first empiric antibiotics suggests that receipt of concordant early antibiotics has a greater impact for some patients, potentially those presenting with critical illness. The decrease in the proportion of patients receiving discordant treatment from the first to the second day of treatment suggests that several patients had treatment started or changed to a concordant regimen between one and two days after blood culture, potentially influenced by clinical factors in the absence of microbiological results.

While previous adult studies show discordant antimicrobial therapy is associated with poorer outcomes, $(1-3,15-21)$ there are very few studies examining the association between discordant antimicrobial therapy and poor outcomes in neonates and children. A recent neonatal sepsis cohort study in India found higher mortality rates among neonates with multidrug-resistant pathogens than those with sensitive isolates (13.4\% vs. 9.4\%, respectively).(22) A few other studies have shown similar associations between antimicrobial resistance and mortality and other adverse outcomes, (23-26) particularly in Gram-negative infections, infections due to ESBL-producing bacteria and those caused by carbapenem-non-susceptible Acinetobacter spp.(27-33) Generally, studies did not explicitly study the concordance of empiric antimicrobial therapy, but rather simply reported on the resistance profile of pathogens. 
The data in our study were voluntarily collected as one module of a large surveillance study and may therefore be subject to selection bias. Most of the sites were tertiary hospitals with the capacity to do voluntary research and not representative of all hospital types in the included countries. We were unable to adjust for centre/country due to wide variation in number of patients enrolled in each.

Clinical data were limited, meaning it was not possible to control for all possible confounders. Although we controlled for presence of a comorbidity, there was a wide range of comorbidity types amongst the patients who died, and we were unable to control for the severity of each comorbidity. Given the way perinatal conditions were classified, it is possible the number of patients with at least one comorbidity was underestimated as some perinatal comorbidities (e.g. asphyxia) might have been underestimated in preterm neonates. Overall the population in our study was quite heterogenous in presentation and covered a wide age range from a number of countries which may limit the ability to extrapolate our findings to specific paediatric sub-populations. However, given the limited data in this area particularly in paediatrics, our findings suggest that more research is needed to inform empiric prescribing regimens within specific sub-populations.

Based on evidence that a higher burden of resistant infections occur in patients $<1$ year and HAl across all age groups are more commonly resistant, we controlled for $\mathrm{HAl}$, comorbidity and age. $(34,35)$ We calculated HAl as 2 or more calendar days after admission, however this may have overestimated the number of HAl since we were unable to calculate it in hours from admission. Although certain pathogens may be associated with mortality and specific comorbidities, our study was insufficiently powered to control for bacterial species, so we opted to control for Gramstain as a proxy.

We were very conservative with our definition of empiric treatment as the time from culture to full speciation and susceptibility is likely more than 2 days in many settings given microbiology capacity and laboratory result reporting systems. (5) The observed high proportion of discordance in the first two days after culture indicates that clinicians likely would not have had microbiology data available at that time. Some residual discordance is expected even after access to susceptibility results due to highly resistant pathogens or lack of access to broader-spectrum treatment.(36,37) Despite our conservative estimate of empiric treatment, we assume some transfer of information (e.g. Gram stain) from microbiology to clinicians must have occurred in this period after culture because a reduction in discordance was observed between the first empiric and overall empiric cohort. We used site-reported SIR (susceptible, intermediate, resistant) for each bug-drug combination, however we used EUCAST interpretive algorithms to define concordance to empiric regimens. We were conservative with our definition of resistant (e.g. 
coding intermediate as resistant) to try to account for any possible differences in breakpoints between Clinical \& Laboratory Standards Institute (CLSI) and EUCAST as some sites used CLSI standards for determining SIR, however interpretive criteria may differ between the two standards.(38)

Even in high income settings it can take more than 50 hours from culture to speciation,(5) with longer timelines in the low and middle income country (LMIC) setting due to lack of microbiology resources.(36) Improving microbiology facilities, particularly in LMIC, to allow for timely processing and dissemination of results from microbiology labs to clinicians is important to improve targeted treatment and to allow for local resistance patterns to be incorporated into institution, national or regional treatment guidelines. $(5,36,39)$ Larger studies in diverse hospital settings will need to be done to quantify the effect of early concordant treatment on survival.

Currently, there is observed high use of broad-spectrum empiric antibiotics not reflecting WHO recommendations, suggesting that clinicians are responding to observed poor outcomes and high resistance rates. $(8,9)$ This has implications for antimicrobial stewardship practices. A straightforward clinically applicable risk assessment, including age, unit type, HAl and other factors, could be one way to reduce empiric broad-spectrum prescribing without negatively impacting mortality.(40) Risk stratification could be used to as a stewardship strategy to identify patients at higher a priori risk of mortality who should be started on broader-spectrum therapy and de-escalated subsequently as well as patients at lower a priori risk who could be started on narrower-spectrum treatment. In order to comprehensively tackle antimicrobial resistance such a risk stratification guideline would need to be implemented alongside other measures including infection prevention and control measures, improved microbiology diagnostics and evaluation of adherence to clinical guidelines.

Despite some limitations, our study indicates increased odds of mortality in neonates and children receiving discordant empiric antibiotic treatment for bloodstream infection in the first 2 days post blood culture. Our findings suggest that early concordant treatment could potentially reduce mortality in this population, perhaps with the largest expected impact in a subgroup of critically ill infants and children with co-morbidities and HAI. In order to achieve this and maintain appropriate levels of broad-spectrum prescribing, future studies will be needed to assess stratifying treatment protocols based on patient risk of adverse outcomes. 


\section{References}

1. Paul M, Shani V, Muchtar E, Kariv G, Robenshtok E, Leibovici L. Systematic Review and Meta-Analysis of the Efficacy of Appropriate Empiric Antibiotic Therapy for Sepsis. Antimicrob Agents Chemother [Internet]. 2010 Nov 1 [cited 2019 Apr 24];54(11):4851-63. Available from: https://aac.asm.org/content/54/11/4851

2. Lodise TP, Patel N, Kwa A, Graves J, Furuno JP, Graffunder E, et al. Predictors of 30-Day Mortality among Patients with Pseudomonas aeruginosa Bloodstream Infections: Impact of Delayed Appropriate Antibiotic Selection. Antimicrob Agents Chemother [Internet]. 2007 Oct 1 [cited 2019 Apr 24];51(10):3510-5. Available from: http://www.ncbi.nlm.nih.gov/pubmed/17646415

3. Kuti EL, Patel AA, Coleman Cl. Impact of inappropriate antibiotic therapy on mortality in patients with ventilator-associated pneumonia and blood stream infection: A meta-analysis. J Crit Care [Internet]. 2008 Mar [cited 2019 Apr 24];23(1):91-100. Available from: http://www.ncbi.nlm.nih.gov/pubmed/18359426

4. Raman G, Avendano E, Berger S, Menon V. Appropriate initial antibiotic therapy in hospitalized patients with gram-negative infections: systematic review and meta-analysis. BMC Infect Dis [Internet]. 2015 Sep 30 [cited 2019 Jul 12];15:395. Available from: http://www.ncbi.nlm.nih.gov/pubmed/26423743

5. MacFadden DR, Leis JA, Mubareka S, Daneman N. The Opening and Closing of Empiric Windows: The Impact of Rapid Microbiologic Diagnostics. Clin Infect Dis [Internet]. 2014 Oct 15 [cited 2019 Jun 13];59(8):1199-200. Available from: https://academic.oup.com/cid/article-lookup/doi/10.1093/cid/ciu493

6. Fuchs A, Bielicki J, Mathur S, Sharland M, Van Den Anker JN. Reviewing the WHO guidelines for antibiotic use for sepsis in neonates and children. Paediatr Int Child Health [Internet]. 2018 Dec 21 [cited 2019 Jan 17];38(sup1):S3-15. Available from: https://www.tandfonline.com/doi/full/10.1080/20469047.2017.1408738

7. Le Doare K, Bielicki J, Heath PT, Sharland M. Systematic Review of Antibiotic Resistance Rates Among GramNegative Bacteria in Children With Sepsis in Resource-Limited Countries. J Pediatric Infect Dis Soc [Internet]. 2015 Mar 1 [cited 2018 Apr 10];4(1):11-20. Available from: https://academic.oup.com/jpids/articlelookup/doi/10.1093/jpids/piu014

8. Jackson C, Hsia Y, Basmaci R, Bielicki J, Heath PT, Versporten A, et al. Global Divergence From World Health Organization Treatment Guidelines for Neonatal and Pediatric Sepsis. Pediatr Infect Dis J. 2019 Aug;1. 
9. Hsia Y, Lee R, Versporten A, Yang Y, Bielicki J, Jackson C, et al. Using the WHO Access/Watch/Reserve classification to define patterns of hospital antibiotic use: analyses of pediatric point prevalence survey data from 56 countries - the first AWaRe PPS. Lancet Glob Heal. 2018;

10. Harris PA, Taylor R, Minor BL, Elliott V, Fernandez M, O’Neal L, et al. The REDCap consortium: Building an international community of software platform partners. J Biomed Inform [Internet]. 2019 Jul 1 [cited 2019 Jul 10];95:103208. Available from: https://www.sciencedirect.com/science/article/pii/S1532046419301261

11. Harris PA, Taylor R, Thielke R, Payne J, Gonzalez N, Conde JG. Research electronic data capture (REDCap) -A metadata-driven methodology and workflow process for providing translational research informatics support. J Biomed Inform [Internet]. 2009 Apr 1 [cited 2019 Jul 10];42(2):377-81. Available from: https://www.sciencedirect.com/science/article/pii/S1532046408001226

12. European Committee on Antimicrobial Susceptibility Testing (EUCAST). EUCAST: Clinical breakpoints and dosing of antibiotics (v9.0) [Internet]. [cited 2019 Feb 16]. Available from: https://eucast.org/clinical_breakpoints/

13. Leclercq R, Cantón R, Brown DFJ, Giske CG, Heisig P, Macgowan AP, et al. EUCAST expert rules in antimicrobial susceptibility testing [Internet]. Vol. 19, Clinical Microbiology and Infection. Blackwell Publishing Ltd; 2013 [cited 2020 Jul 22]. p. 141-60. Available from: http://www.eucast.org

14. ICH. ICH HARMONISED GUIDELINE ADDENDUM TO ICH E11: CLINICAL INVESTIGATION OF MEDICINAL PRODUCTS IN THE PEDIATRIC POPULATION E11 (R1). 2017.

15. Stewardson AJ, Marimuthu K, Sengupta S, Allignol A, El-Bouseary M, Carvalho MJ, et al. Effect of carbapenem resistance on outcomes of bloodstream infection caused by Enterobacteriaceae in low-income and middleincome countries (PANORAMA): a multinational prospective cohort study. Lancet Infect Dis [Internet]. 2019 Jun 1 [cited 2019 Jun 12];19(6):601-10. Available from: http://www.ncbi.nlm.nih.gov/pubmed/31047852

16. Schwaber MJ, Carmeli Y. The effect of antimicrobial resistance on patient outcomes: importance of proper evaluation of appropriate therapy. Crit Care [Internet]. 2009 [cited 2019 Jul 12];13(1):106. Available from: http://www.ncbi.nlm.nih.gov/pubmed/19216721

17. Schwaber MJ, Carmeli Y. Mortality and delay in effective therapy associated with extended-spectrum - 
lactamase production in Enterobacteriaceae bacteraemia: a systematic review and meta-analysis. J Antimicrob Chemother [Internet]. 2007 Sep 17 [cited 2019 Jul 12];60(5):913-20. Available from: http://www.ncbi.nlm.nih.gov/pubmed/17848376

18. Hyle EP, Lipworth AD, Zaoutis TE, Nachamkin I, Bilker WB, Lautenbach E. Impact of Inadequate Initial Antimicrobial Therapy on Mortality in Infections Due to Extended-Spectrum $\beta$-Lactamase-Producing Enterobacteriaceae. Arch Intern Med [Internet]. 2005 Jun 27 [cited 2019 Jul 12];165(12):1375. Available from: http://archinte.jamanetwork.com/article.aspx?doi=10.1001/archinte.165.12.1375

19. Bonine NG, Berger A, Altincatal A, Wang R, Bhagnani T, Gillard P, et al. Impact of Delayed Appropriate Antibiotic Therapy on Patient Outcomes by Antibiotic Resistance Status From Serious Gram-negative Bacterial Infections. Am J Med Sci. 2019 Feb 1;357(2):103-10.

20. Kohler PP, Volling C, Green K, Uleryk EM, Shah PS, McGeer A. Carbapenem Resistance, Initial Antibiotic Therapy, and Mortality in Klebsiella pneumoniae Bacteremia: A Systematic Review and Meta-Analysis. Infect Control Hosp Epidemiol [Internet]. 2017 Nov 27 [cited 2019 Jul 12];38(11):1319-28. Available from: https://www.cambridge.org/core/product/identifier/S0899823X17001970/type/journal_article

21. Okeke IN, Laxminarayan R, Bhutta ZA, Duse AG, Jenkins $P, O^{\prime} B$ rien TF, et al. Antimicrobial resistance in developing countries. Part I: recent trends and current status. Lancet Infect Dis [Internet]. 2005 Aug 1 [cited 2018 Sep 10];5(8):481-93. Available from:

https://www.sciencedirect.com/science/article/pii/S1473309905701894?via\%3Dihub

22. Investigators of the Delhi Neonatal Infection Study (DeNIS) collaboration. Characterisation and antimicrobial resistance of sepsis pathogens in neonates born in tertiary care centres in Delhi, India: a cohort study. Lancet Glob Heal [Internet]. 2016 Oct [cited 2019 Jul 15];4(10):e752-60. Available from: http://www.ncbi.nlm.nih.gov/pubmed/27633433

23. Peters L, Olson L, Khu DTK, Linnros S, Le NK, Hanberger H, et al. Multiple antibiotic resistance as a risk factor for mortality and prolonged hospital stay: A cohort study among neonatal intensive care patients with hospital-acquired infections caused by gram-negative bacteria in Vietnam. PLoS One [Internet]. 2019 [cited 2019 Jul 12];14(5):e0215666. Available from: http://www.ncbi.nlm.nih.gov/pubmed/31067232 
24. Folgori L, Livadiotti S, Carletti M, Bielicki J, Pontrelli G, Ciofi Degli Atti ML, et al. Epidemiology and Clinical Outcomes of Multidrug-resistant, Gram-negative Bloodstream Infections in a European Tertiary Pediatric Hospital During a 12-month Period. Pediatr Infect Dis J [Internet]. 2014 Sep [cited 2019 Jul 12];33(9):929-32. Available from: http://www.ncbi.nlm.nih.gov/pubmed/24642515

25. Foglia EE, Fraser VJ, Elward AM. Effect of Nosocomial Infections Due to Antibiotic-Resistant Organisms on Length of Stay and Mortality in the Pediatric Intensive Care Unit. Infect Control Hosp Epidemiol [Internet]. 2007 Mar 2 [cited 2019 Jul 12];28(3):299-306. Available from:

http://www.ncbi.nlm.nih.gov/pubmed/17326020

26. Ivády B, Kenesei É, Tóth-Heyn P, Kertész G, Tárkányi K, Kassa C, et al. Factors influencing antimicrobial resistance and outcome of Gram-negative bloodstream infections in children. Infection [Internet]. 2016 Jun 6 [cited 2019 Jul 12];44(3):309-21. Available from: http://link.springer.com/10.1007/s15010-015-0857-8

27. Abdel-Hady H, Hawas S, El-Daker M, El-Kady R. Extended-spectrum $\beta$-lactamase producing Klebsiella pneumoniae in neonatal intensive care unit. J Perinatol [Internet]. 2008 Oct 26 [cited 2019 Jul 12];28(10):685-90. Available from: http://www.ncbi.nlm.nih.gov/pubmed/18580881

28. Kayange N, Kamugisha E, Mwizamholya DL, Jeremiah S, Mshana SE. Predictors of positive blood culture and deaths among neonates with suspected neonatal sepsis in a tertiary hospital, Mwanza-Tanzania. BMC Pediatr [Internet]. 2010 Jun 4 [cited 2019 Jul 12];10:39. Available from: http://www.ncbi.nlm.nih.gov/pubmed/20525358

29. Ariffin $\mathrm{H}$, Navaratnam $\mathrm{P}$, Mohamed M, Arasu A, Ariffin Abdullah W, Lee Lee C, et al. Ceftazidime-resistant Klebsiella pneumoniae bloodstream infection in children with febrile neutropenia. Int J Infect Dis [Internet]. 2000 Jan 1 [cited 2019 Jul 12];4(1):21-5. Available from: https://www.sciencedirect.com/science/article/pii/S1201971200900614

30. Zaoutis TE, Goyal M, Chu JH, Coffin SE, Bell LM, Nachamkin I, et al. Risk factors for and outcomes of bloodstream infection caused by extended-spectrum beta-lactamase-producing Escherichia coli and Klebsiella species in children. Pediatrics [Internet]. 2005 Apr 1 [cited 2017 Nov 27];115(4):942-9. Available from: http://www.ncbi.nlm.nih.gov/pubmed/15805368 
31. Thatrimontrichai A, Apisarnthanarak A, Chanvitan P, Janjindamai W, Dissaneevate S, Maneenil G. Risk Factors and Outcomes of Carbapenem-resistant Acinetobacter baumannii Bacteremia in Neonatal Intensive Care Unit. Pediatr Infect Dis J [Internet]. 2013 Feb [cited 2019 Jul 12];32(2):140-5. Available from: http://content.wkhealth.com/linkback/openurl?sid=WKPTLP:landingpage\&an=00006454-201302000-00010

32. Punpanich W, Nithitamsakun N, Treeratweeraphong V, Suntarattiwong P. Risk factors for carbapenem nonsusceptibility and mortality in Acinetobacter baumannii bacteremia in children. Int J Infect Dis [Internet]. 2012 Nov [cited 2019 Jul 12];16(11):e811-5. Available from: http://www.ncbi.nlm.nih.gov/pubmed/22898148

33. Saleem AF, Ahmed I, Mir F, Ali SR, Zaidi AK. Pan-resistant Acinetobacter Infection in Neonates in Karachi, Pakistan. J Infect Dev Ctries [Internet]. 2010 Feb 1 [cited 2019 Jul 12];4(01):030-7. Available from: http://www.jidc.org/index.php/journal/article/view/533

34. Cassini A, Högberg LD, Plachouras D, Quattrocchi A, Hoxha A, Simonsen GS, et al. Attributable deaths and disability-adjusted life-years caused by infections with antibiotic-resistant bacteria in the EU and the European Economic Area in 2015: a population-level modelling analysis. Lancet Infect Dis. 2019 Jan $1 ; 19(1): 56-66$.

35. Peters Id L, Olson L, Khu DTK, Linnros S, Le NK, Hanberger $\mathrm{H}$, et al. Multiple antibiotic resistance as a risk factor for mortality and prolonged hospital stay: A cohort study among neonatal intensive care patients with hospital-acquired infections caused by gram-negative bacteria in Vietnam. 2019 [cited 2019 Dec 4]; Available from: https://doi.org/10.1371/journal.pone.0215666

36. Rudd KE, Kissoon N, Limmathurotsakul D, Bory S, Mutahunga B, Seymour CW, et al. The global burden of sepsis: barriers and potential solutions. Crit Care [Internet]. 2018 Dec 23 [cited 2019 Jul 26];22(1):232. Available from: https://ccforum.biomedcentral.com/articles/10.1186/s13054-018-2157-z

37. Laxminarayan R, Matsoso P, Pant S, Brower C, Røttingen J-A, Klugman K, et al. Access to effective antimicrobials: a worldwide challenge. Lancet [Internet]. 2016 Jan 9 [cited 2019 Jul 16];387(10014):168-75. Available from: https://www.sciencedirect.com/science/article/pii/S0140673615004742?via\%3Dihub

38. Cusack TP, Ashley EA, Ling CL, Roberts T, Turner P, Wangrangsimakul T, et al. Time to switch from CLSI to 
EUCAST? A Southeast Asian perspective [Internet]. Vol. 25, Clinical Microbiology and Infection. Elsevier B.V.; 2019 [cited 2020 Aug 13]. p. 782-5. Available from: https://doi.org/10.1016/j.cmi.2019.03.007.

39. Dellinger RP, Levy MM, Rhodes A, Annane D, Gerlach H, Opal SM, et al. Surviving Sepsis Campaign: International Guidelines for Management of Severe Sepsis and Septic Shock, 2012. Intensive Care Med [Internet]. 2013 Feb [cited 2019 Aug 2];39(2):165-228. Available from:

http://link.springer.com/10.1007/s00134-012-2769-8

40. Bielicki JA, Sharland M, Versporten A, Goossens H, Cromwell DA. Using risk adjustment to improve the interpretation of global inpatient pediatric antibiotic prescribing. Kou YR, editor. PLoS One [Internet]. 2018 Jul 6 [cited 2019 Jul 26];13(7):e0199878. Available from: https://dx.plos.org/10.1371/journal.pone.0199878 


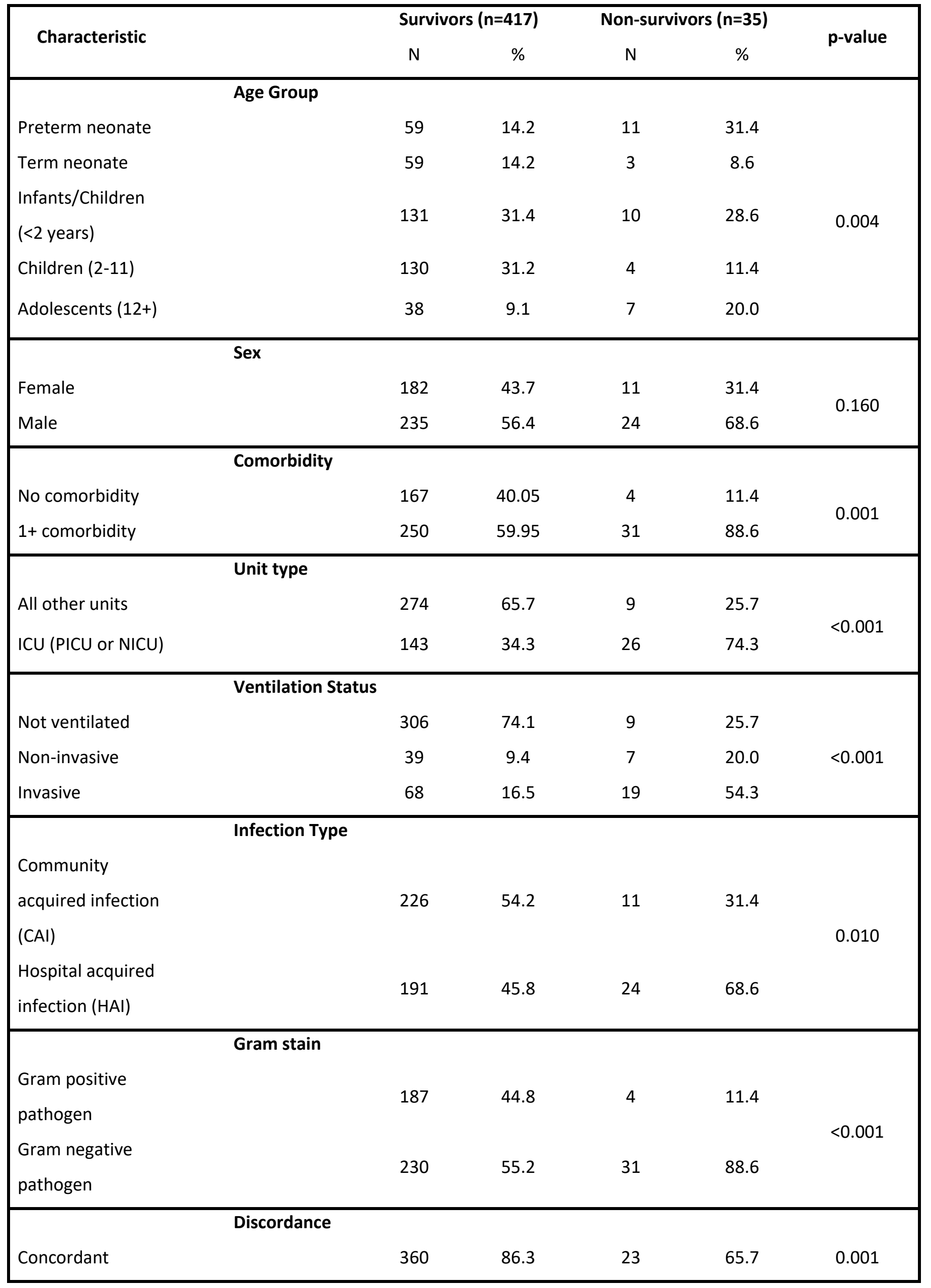


Table 2. Concordance and discordance of empiric regimen by pathogen with fatalities* from overall cohort ( $n=452$ overall).

\begin{tabular}{|c|c|c|c|c|c|}
\hline \multirow{2}{*}{\multicolumn{3}{|c|}{ Pathogen }} & \multicolumn{2}{|c|}{ 30-day Case Fatality } & \multirow{3}{*}{$\begin{array}{c}\text { Total } \\
79(90.8 \%\end{array}$} \\
\hline & & & \multirow{2}{*}{$\begin{array}{l}\text { Survivor } \\
76(96 \%)\end{array}$} & \multirow{2}{*}{$\begin{array}{c}\text { Non-survivor } \\
3(4 \%)\end{array}$} & \\
\hline \multirow{3}{*}{ Staphylococcus aureus } & \multirow{2}{*}{$\begin{array}{c}\text { Empiric } \\
\text { treatment }\end{array}$} & \multirow{2}{*}{$\begin{array}{l}\text { Concordant } \\
\text { Discordant }\end{array}$} & & & \\
\hline & & & $8(100 \%)$ & $0(0 \%)$ & $8(9.2 \%)$ \\
\hline & \multicolumn{2}{|c|}{ Total } & $84(96.6 \%)$ & $3(3.4 \%)$ & $87(100 \%)$ \\
\hline \multirow{3}{*}{ Escherichia coli } & \multirow{2}{*}{$\begin{array}{l}\text { Empiric } \\
\text { treatment }\end{array}$} & \multirow{2}{*}{$\begin{array}{l}\text { Concordant } \\
\text { Discordant }\end{array}$} & $67(92 \%)$ & $6(8 \%)$ & $73(90.1 \%)$ \\
\hline & & & $5(62 \%)$ & $3(38 \%)$ & $8(9.9 \%)$ \\
\hline & \multicolumn{2}{|c|}{ Total } & $72(88.9 \%)$ & $9(11.1 \%)$ & $81(100 \%)$ \\
\hline \multirow{3}{*}{ Klebsiella spp. } & \multirow{2}{*}{$\begin{array}{l}\text { Empiric } \\
\text { treatment }\end{array}$} & \multirow{3}{*}{$\begin{array}{l}\text { Concordant } \\
\text { Discordant }\end{array}$} & $41(89 \%)$ & $5(11 \%)$ & $46(83.6 \%)$ \\
\hline & & & $8(89 \%)$ & $1(11 \%)$ & $9(16.4 \%)$ \\
\hline & & & 49 (89.1\%) & $6(10.9 \%)$ & $55(100 \%)$ \\
\hline \multirow{3}{*}{ Enterobacter spp. } & \multirow{2}{*}{$\begin{array}{l}\text { Empiric } \\
\text { treatment }\end{array}$} & \multirow{2}{*}{$\begin{array}{l}\text { Concordant } \\
\text { Discordant }\end{array}$} & 21 91\%) & $2(9 \%)$ & $23(82.1 \%)$ \\
\hline & & & $2(40 \%)$ & $3(60 \%)$ & $5(17.9 \%)$ \\
\hline & \multicolumn{2}{|c|}{ Total } & $23(82.1 \%)$ & $5(17.9 \%)$ & $28(100 \%)$ \\
\hline \multirow{3}{*}{$\begin{array}{c}\text { Pseudomonas } \\
\text { aeruginosa }\end{array}$} & \multirow{2}{*}{$\begin{array}{l}\text { Empiric } \\
\text { treatment }\end{array}$} & \multirow{2}{*}{$\begin{array}{l}\text { Concordant } \\
\text { Discordant }\end{array}$} & $18(86 \%)$ & $3(14 \%)$ & $21(95.5 \%)$ \\
\hline & & & $0(0 \%)$ & $1(100 \%)$ & $1(4.5 \%)$ \\
\hline & \multicolumn{2}{|c|}{ Total } & $18(81.8 \%)$ & $4(18.2 \%)$ & $22(100 \%)$ \\
\hline \multirow{3}{*}{$\begin{array}{c}\text { Acinetobacter } \\
\text { baumannii }\end{array}$} & \multirow{2}{*}{$\begin{array}{c}\text { Empiric } \\
\text { treatment }\end{array}$} & \multirow{2}{*}{$\begin{array}{l}\text { Concordant } \\
\text { Discordant }\end{array}$} & $5(71 \%)$ & $2(29 \%)$ & $7(50 \%)$ \\
\hline & & & $5(71 \%)$ & $2(29 \%)$ & $7(50 \%)$ \\
\hline & \multicolumn{2}{|c|}{ Total } & $10(71.4 \%)$ & $4(28.6 \%)$ & $14(100 \%)$ \\
\hline \multirow{3}{*}{ Serratia spp. } & \multirow{2}{*}{$\begin{array}{l}\text { Empiric } \\
\text { treatment }\end{array}$} & \multirow{2}{*}{$\begin{array}{l}\text { Concordant } \\
\text { Discordant }\end{array}$} & $7(87 \%)$ & $1(13 \%)$ & $10(71.4 \%)$ \\
\hline & & & $2(50 \%)$ & $2(50 \%)$ & $4(28.6 \%)$ \\
\hline & \multicolumn{2}{|c|}{ Total } & $11(78.6 \%)$ & $3(21.4 \%)$ & $14(100 \%)$ \\
\hline \multirow{3}{*}{$\begin{array}{c}\text { Streptococcus } \\
\text { pyogenes }\end{array}$} & Empiric & Concordant & $8(89 \%)$ & $1(11 \%)$ & $9(90.0 \%)$ \\
\hline & treatment & Discordant & $1(100 \%)$ & $0(0 \%)$ & $1(10.0 \%)$ \\
\hline & & & $9(90.0 \%)$ & $1(10.0 \%)$ & 10 (100\%) \\
\hline & Total & & 276 & 35 & 311 \\
\hline
\end{tabular}

*Salmonella spp., Streptococcus pneumoniae, Streptococcus agalactiae, Enterococcus faecalis, Enterococcus faecium, Enterococcus spp., Haemophilus influenza, Burkholderia cepacia and Proteus spp. had no fatalities. Concordance and discordance of these pathogens are presented in table, Supplemental Digital Content 6. 

culture.

\begin{tabular}{|c|c|c|}
\hline \multirow[t]{2}{*}{ Characteristic } & \multicolumn{2}{|c|}{$\begin{array}{l}\text { Patients with no early antibiotics } \\
\qquad(\mathrm{n}=34)\end{array}$} \\
\hline & $\mathrm{N}$ & $\%$ \\
\hline \multicolumn{3}{|l|}{ Age Group } \\
\hline Preterm neonate & 3 & 9 \\
\hline Term neonate & 1 & 3 \\
\hline Infants/Children (<2 years) & 11 & 32 \\
\hline Children (2-11) & 15 & 44 \\
\hline Adolescents (12+) & 4 & 12 \\
\hline \multicolumn{3}{|l|}{ Sex } \\
\hline Female & 11 & 32 \\
\hline Male & 23 & 68 \\
\hline \multicolumn{3}{|l|}{ Comorbidity } \\
\hline No comorbidity & 19 & 56 \\
\hline $1+$ comorbidity & 15 & 44 \\
\hline \multicolumn{3}{|l|}{ Unit type } \\
\hline All other units & 25 & 74 \\
\hline ICU (PICU or NICU) & 9 & 25 \\
\hline \multicolumn{3}{|l|}{ Ventilation Status } \\
\hline Not ventilated & 26 & 79 \\
\hline Non-invasive & 3 & 9 \\
\hline Invasive & 4 & 12 \\
\hline \multicolumn{3}{|l|}{ Infection Type } \\
\hline Community acquired infection (CAI) & 24 & 71 \\
\hline Hospital acquired infection (HAI) & 10 & 29 \\
\hline \multicolumn{3}{|l|}{ Gram stain } \\
\hline Gram positive pathogen & 11 & 32 \\
\hline Gram negative pathogen & 23 & 68 \\
\hline \multicolumn{3}{|l|}{ Pathogen } \\
\hline Salmonella spp. (NTS* \& typhi) & 8 & 24 \\
\hline Klebsiella spp. & 7 & 21 \\
\hline Staphylococcus aureus & 6 & 18 \\
\hline Enterobacter spp. & 4 & 12 \\
\hline Enterococcus faecalis & 2 & 6 \\
\hline
\end{tabular}




\begin{tabular}{|ccc|} 
Streptococcus pneumoniae & 2 & 6 \\
Escherichia. coli & 1 & 3 \\
Proteus spp. & 1 & 3 \\
Pseudomonas aeruginosa & 1 & 3 \\
Serratia spp. & 1 & 3 \\
Streptococcus pyogenes & 1 & 3 \\
\hline Outcome & 32 & 94 \\
Survived & 2 & 6 \\
\hline Died &
\end{tabular}

*Nontyphoidal Salmonella 
Table 4. Univariable Cochran-Mantel-Haenszel odds ratios for 30-day all-cause mortality.

\begin{tabular}{|c|c|c|c|}
\hline $\begin{array}{c}\text { Predictors of 30-day } \\
\text { mortality }\end{array}$ & OR & $95 \% \mathrm{Cl}$ & O-value \\
\cline { 2 - 4 } & 0.8 & $0.6-1.1$ & 0.2037 \\
\hline $\begin{array}{c}\text { Age Group (ref: pre-term } \\
\text { neonate) }\end{array}$ & 1.9 & $0.8-3.5$ & 0.1610 \\
Sex (ref: female) & 5.2 & $1.8-15.2$ & 0.0008 \\
Comorbidity (ref: none) & 5.5 & $2.5-12.4$ & $<0.0001$ \\
Unit Type (ref: non-ICU) & 3.9 & $2.5-5.9$ & $<0.0001$ \\
Ventilation Status (ref: none) & 2.6 & $1.2-5.4$ & 0.0097 \\
Infection Type (ref: CAI) & & & 0.0007 \\
Pathogen Type (ref: Gram & 6.3 & $2.1-18.5$ & \\
positive) & & & \\
\hline
\end{tabular}




\begin{tabular}{|l|c|c|c|}
\hline Model & \multicolumn{1}{|c|}{$\begin{array}{c}\text { Overall }(\mathbf{n}=\mathbf{4 5 2}) \\
\text { Odds Ratio }(95 \% \mathrm{Cl}, \mathrm{p})\end{array}$} & $\begin{array}{c}\text { First empiric regimen } \\
(\mathbf{n = 4 5 1})^{1} \\
\text { Odds Ratio }(95 \% \mathrm{Cl}, \mathrm{p})\end{array}$ & $\begin{array}{c}\text { First empiric regimen } \\
\text { subset }(\mathbf{n = 4 1 7})^{2} \\
\text { Odds Ratio }(95 \% \mathrm{Cl}, \mathrm{p})\end{array}$ \\
\hline $\begin{array}{l}\text { Unadjusted OR } \\
\text { (discordance) } \\
\begin{array}{l}\text { Adjusted OR (all } \boldsymbol{a} \\
\text { priori variables }\end{array}\end{array}$ & $3.3(1.5-7.1,0.0011)$ \\
$\begin{array}{l}\text { Adjusted OR (only } \\
\text { variables } \\
\text { significant in } \\
\text { model) }\end{array}$ & $2.9(1.2-7.0,0.015)$ & $2.2(1.01-4.9,0.046)$ & $2.5(1.1-5.9,0.029)$ \\
\hline
\end{tabular}

${ }^{1}$ antibiotics given in first day post blood culture (patients who received no antibiotics in first day post blood culture coded as discordant)

${ }^{2}$ excluding 34 patients who received no antibiotics in the first day post blood culture

${ }^{3}$ adjusted for age group, sex, presence of comorbidity, unit type, type of infection (e.g. HAI), Gram stain of pathogen ${ }^{4}$ adjusted for age group, presence of comorbidity, unit type and Gram stain of pathogen

${ }^{5}$ adjusted for presence of comorbidity, unit type and Gram stain of pathogen 